AperTO - Archivio Istituzionale Open Access dell'Università di Torino

Clinico-pathologic features of primary melanoma and sentinel lymph node predictive for nonsentinel lymph node involvement and overall survival in melanoma patients: A single centre observational cohort study.

This is the author's manuscript

Original Citation:

Availability:

This version is available http://hdl.handle.net/2318/80936

since 2021-11-01T15:34:08Z

Published version:

DOI:10.1016/j.suronc.2010.11.001

Terms of use:

Open Access

Anyone can freely access the full text of works made available as "Open Access". Works made available under a Creative Commons license can be used according to the terms and conditions of said license. Use of all other works requires consent of the right holder (author or publisher) if not exempted from copyright protection by the applicable law. 


\section{(3) \\ UNIVERSITÀ DEGLI STUDI DI TORINO}

This Accepted Author Manuscript (AAM) is copyrighted and published by Elsevier. It is posted here by agreement between Elsevier and the University of Turin. Changes resulting from the publishing process - such as editing, corrections, structural formatting, and other quality control mechanisms - may not be reflected in this version of the text. The definitive version of the text was subsequently published in

Surg Oncol. 2011 Dec;20(4):259-64. doi: 10.1016/j.suronc.2010.11.001. Epub 2010 Dec 9.

Clinico-pathologic features of primary melanoma and sentinel lymph node predictive for nonsentinel lymph node involvement and overall survival in melanoma patients: a single centre observational cohort study.

Quaglino P, Ribero S, Osella-Abate S, Macrì L, Grassi M, Caliendo V, Asioli S, Sapino A, Macripò G, Savoia P, Bernengo MG.

You may download, copy and otherwise use the AAM for non-commercial purposes provided that your license is limited by the following restrictions:

(1) You may use this AAM for non-commercial purposes only under the terms of the CC-BY-NC-ND license.

(2) The integrity of the work and identification of the author, copyright owner, and publisher must be preserved in any copy.

(3) You must attribute this AAM in the following format: Creative Commons BY-NC-ND license (http://creativecommons.org/licenses/by-nc-nd/4.0/deed.en) 
Surgical Oncology

Volume 20, Issue 4, December 2011, Pages 259-264

http://dx.doi.org/10.1016/j.suronc.2010.11.001

Review

\title{
Clinico-pathologic features of primary melanoma and sentinel lymph node predictive for non-sentinel lymph node involvement and overall survival in melanoma patients: A single centre observational cohort study.
}

P. Quaglino ${ }^{a * 1}$, S. Ribero ${ }^{c 1}$, S. Osella-Abate ${ }^{a}$, L. Macri ${ }^{b}$, M. Grassi ${ }^{c}$, V. Caliendo ${ }^{c}$, S. Asioli ${ }^{b}$ A. Sapino $^{b}$, G. Macripò ${ }^{c}$, P. Savoia ${ }^{a}$, M.G. Bernengo ${ }^{a}$

${ }^{a}$ Department of Biomedical Sciences and Human Oncology, Section of Dermatology, 1st Dermatologic Division, University of Turin, Italy

${ }^{\mathrm{b}}$ Section of Surgical Pathology University of Turin, Italy

c Section of Dermatologic Surgery, Oncology and Haematology Department, San Giovanni Hospital Turin, Italy

* Corresponding author.

E-mail address: pietro.quaglino@unito.it (P. Quaglino).

${ }^{1}$ Both authors contributed equally.

\begin{abstract}
Objective: Completion Lymph Node Dissection (CLND) is the current standard of practice for patients with a positive Sentinel Lymph Node Biopsy (SLNB). Significant morbidity is associated to CLND, so we tried to evaluate which prognostic variables could predict NSLN invasion in SLN-positive patients and their impact on the overall survival (OS).

Methods: A retrospective chart review of 603 patients that had undergone SLNB for melanoma between 2000 and 2009 at our department was done. 100 SLN were positive at the histopathological analysis of SLN. Demographic variables, primary melanoma, SLN pathologic features and results of CLND were analysed. Multivariate logistic regression and OS analyses were carried out to test the prognostic relevance of clinicopathologic variables on CLND results and disease course.

Results: Breslow thickness, ulceration and micro/macrometastatic pattern of SLN invasion carried a significantly independent higher likelihood of NSLN involvement; Starz classification did not maintain a statistical significance in multivariate analysis. Only one patient (4.3\%) without adverse prognostic factors showed NSLN involvement, which was found in $33.3 \%$ of patients with one and $55.9 \%$ with two or more adverse parameters $(p=0.0001)$. OS analyses confirmed the prognostic significance of these factors. Conclusion: Waiting for the results of Multicenter Selective Lymphadenectomy Trial II, our study suggests a clinically useful and easily applicable means of identifying patients with an unfavourable disease course. The presence of one or more adverse factors identifies patients in whom CLND is mandatory to include thereafter in a more strict follow-up program. Moreover, the finding of no adverse prognostic indicators
\end{abstract}


associated to the presence of significant co-morbidities and/or elderly age, could be useful in identifying patients not to treat by CLND.

Keywords: Melanoma; Overall survival; Non-sentinel lymph nodes

\section{Introduction}

Since the introduction of sentinel lymph node biopsy (SLNB) from Morton et al. [1] in early 1990s for patients with melanoma, this approach has been established as a diagnostic procedure in melanoma. SLNB represents the to-date most accurate staging procedure for the early identification of regional node metastases. Micrometastases in sentinel lymph node are prognostically significant in melanoma [2] and were therefore included in the revised American Joint Committee on Cancer (AJCC) Classification [3]. The finding of a positive SLN identify patients who might benefit from completion lymph node dissection (CLND) [4]. However, CLND carries significant morbidity [5] and [6] and there is no consensus on the benefit of a completion dissection in melanoma patients. In fact reports in the literature showed that only from 14 to $28 \%$ [7], [8], [9], [10] and [11] of positive patients will harbour further disease in the affected basin. Theoretically, only patients with involvement of additional, non-sentinel lymph nodes (NSLN) in the CLND specimen should benefit from a CLND. This suggests that a large percentage of patients may undergo an unnecessary, morbid procedure for no apparent gain [12], [13], [14], [15] and [16]. Recent efforts have been made to identify those patients least likely to have a metastatic disease in the NSLN, who may potentially avoid a further surgical operation [17], [18], [19], [20] and [21].

The objective of this study was to identify which clinico-pathologic features of primary melanoma and SLN are predictive for NSLN involvement and to further ascertain their prognostic role by assessing their relationship with the clinical course in terms of OS.

\section{Materials and methods}

\section{Patients, lymphatic mapping, sentinel lymph node biopsy and completion lymphadenectomy}

SLNB was performed in 603 primary melanoma patients in our Department from January 2000 until March 2009, the follow-up was extended until December 2009. An SLN involvement was found in 100/603 patients (16.6\%). Patients were enrolled on the basis of guideline criteria [3], [22], [23] and [24]. SLN was performed in the presence of melanoma $>1 \mathrm{~mm}$, or even lower if ulcerated or Clark IV-V or presence of mitoses more than or equal to $1 / \mathrm{mm} 2$. SLNB was not performed in patients aged more than 75 years. Staging for visceral occult metastases before SLNB was performed according to national Italian guidelines [22]. Patients with primary melanoma less than or equal to $2 \mathrm{~mm}$ without ulceration underwent chest $X$ rays and abdomen ultrasound, whereas patients with deeper Breslow thickness performed brain, lung and abdomen computed tomography (CT). At the time of SLNB, there was no clinical or radiological evidence of melanoma metastases.

The SLNs were detected by lymphoscintigraphy and patent blue dye. All radio-labeled lymph nodes were considered to be SLN and excised. A median number of 2 sentinel nodes (range: 1-4) were removed. SLNs were fixed in formaldehyde and bisected along the long axis of the ilar region [25]. Depending of its size, the bisected nodes were embedded in one or more paraffin blocks. Paraplast sections at five intervals of $50 \mu \mathrm{m}$ were prepared from each paraffin block. From each paraplast section, four slides were made and 
stained with conventional histopathology (hematoxylin-eosin) and immuno-hystochemistry (S-100 and HMB-45).

The pattern of SLN involvement was defined as macro- or microscopic on the basis of the presence or absence, respectively, of gross extracapsular extension [3].

The penetration depth was measured with an ocular micrometer as maximum distance of tumour cells from the interior margin of the lymph node capsule, as described by Starz et al. [17]. Presence of tumour cells up to $0.3 \mathrm{~mm}$ was classified as Starz-I, invasion between $0.3 \mathrm{~mm}$ and $1.0 \mathrm{~mm}$ was Starz-II, and a deeper invasion meant Starz-III. The NSLN were analysed only with H\&E.

Patient's characteristics included: 1) demographic data (sex, age); 2) histologic features of the primary melanoma (Breslow thickness, Clark level, histologic subtype, ulceration); 3) data from the SLN included: number of SLN removed, number of positive SLNs, localisation of SLN (head/neck, axilla, inguinal), pattern of invasion (micro-/macro-metastases), depth invasion of metastatic cells in the SLN (Starz Classification 2004) [17]. The mitotic rate was recorded for all patients but it was not taken into consideration for this study purposes in as much as according to the updated AJCC classification [3] was not shown to carry a prognostic relevance in the disease outcome of stage III patients.

\section{Statistical analyses}

Statistical analyses were performed using the SPSS 17 Statistical Software. Both parametric and non-parametric tests were used; only " $p$ " values of parametric tests were reported, as the results of the two tests were similar. Univariate and multivariate logistic regression were used to test for the significance of the predictor variables' association with NSLN metastases. Overall survival (OS) was calculated from the surgical excision of SLN to the date of death or last check-up for all patients. Survival estimates were derived by the Kaplan-Meier method [26] and the statistical comparison was done by the log-rank test [27]. Univariate analyses were carried out to evaluate the prognostic role of different variables.

\section{Results}

\section{Clinico-pathologic variables associated to NSLN involvement}

Patients characteristics with regard to clinical data, primary melanoma, SLN and CLND are given in Table 1 according to the presence of NSLN involvement which was detected in 31 out of 100 of patients (Table 1).

Univariate logistic regression showed that the parameters associated with a higher likelihood of NSLN involvement were Breslow thickness, ulceration, micro-/macro-metastatic pattern and Starz classification. In particular, the odds ratio (OR) was 1.52 for Breslow thickness, 4.59 for ulceration, 6.42 for the micro/macro-metastatic pattern and 2.32 for the Starz classification [17] (Table 2). The highest percentages of NSLN involvement were found in patients with Breslow thickness $>4 \mathrm{~mm}(52 \%)$, ulceration (53.6\%), macro-metastatic pattern (70\%) and grade III Starz classification (40\%). On the other hand, NSLN involvement after a positive SLN was found in $11.5 \%$ of patients with thin primary (between 1 and $2 \mathrm{~mm}$ ) and $5.5 \%$ Starz I. 
Multivariate logistic regression confirmed the independent prognostic role on NSLN involvement for Breslow thickness, ulceration and micro-/macrometastatic pattern, whilst Starz classification did not maintain a statistical significance. Only one patient (4.3\%) without adverse prognostic factors (i.e. Breslow thickness $\leq 2 \mathrm{~mm}$; no ulceration; SLN micro-metastatic pattern) showed NSLN involvement, whilst the percentage increased to $33.3 \%$ for one adverse indicator and $55.9 \%$ for two or more ( $p=0.0001$, OR 4.4; confidence intervals 2.1-9.0).

Table 1

Patient characteristics according to the presence of NSLN involvement.

\begin{tabular}{|c|c|c|}
\hline & & $\begin{array}{l}\text { NSLN positive } \\
(n=31 / 100))\end{array}$ \\
\hline \multirow[t]{2}{*}{ Gender } & Female & $12 / 41(29.3 \%)$ \\
\hline & Male & $19 / 59(32.0 \%)$ \\
\hline \multirow[t]{4}{*}{ Type of melanoma } & Superficial spreading & $17 / 70(24.3 \%)$ \\
\hline & Acral lentiginous & $2 / 6(33.3 \%)$ \\
\hline & Nodular & $12 / 22(45.3 \%)$ \\
\hline & Lentigo maligna & $0 / 2(0 \%)$ \\
\hline \multirow[t]{3}{*}{ Breslow thickness } & $1,01-2 \mathrm{~mm}$ & $3 / 26(11.5 \%)$ \\
\hline & $2,01-4 \mathrm{~mm}$ & $15 / 49(30.6 \%)$ \\
\hline & $>4 \mathrm{~mm}$ & $13 / 25(52 \%)$ \\
\hline \multirow[t]{3}{*}{ Clark level } & III & $6 / 32(15.8 \%)$ \\
\hline & IV & $22 / 60(36.7 \%)$ \\
\hline & V & $3 / 8(37.5 \%)$ \\
\hline \multirow[t]{2}{*}{ Ulceration } & Yes & $15 / 28(53.6 \%)$ \\
\hline & No & $16 / 72(22.2 \%)$ \\
\hline \multirow{3}{*}{ Primary site } & Head/neck & $2 / 8(25.0 \%)$ \\
\hline & Trunk & $12 / 42(28.6 \%)$ \\
\hline & Extremities & $17 / 50(34 \%)$ \\
\hline \multirow[t]{2}{*}{ Number of SLN } & 1 & $15 / 45(33.3 \%)$ \\
\hline & $>1$ & $16 / 54(29.6 \%)$ \\
\hline \multirow[t]{3}{*}{ CLND site } & Neck & $3 / 9(33.3 \%)$ \\
\hline & Axillary & $9 / 42(21.4 \%)$ \\
\hline & Inguinal & $19 / 49(38.8 \%)$ \\
\hline \multirow{4}{*}{$\begin{array}{l}\text { Number of lymph nodes } \\
\text { obtained by CLND }\end{array}$} & $1-10$ & $5 / 14(35.7 \%)$ \\
\hline & $11-20$ & $16 / 49(32.6 \%)$ \\
\hline & $21-30$ & $5 / 22(22.7 \%)$ \\
\hline & $>30$ & $5 / 15(33.3 \%)$ \\
\hline \multirow{2}{*}{ Number of positive SLNs } & 1 & $22 / 77(28.6 \%)$ \\
\hline & $>1$ & $9 / 23(39.1 \%)$ \\
\hline \multirow[t]{2}{*}{ Pattern of SLN invasion } & Micrometastases & $24 / 90(26.7 \%)$ \\
\hline & Macrometastases & $7 / 10(70 \%)$ \\
\hline \multirow[t]{3}{*}{ Starz classification } & SI & $1 / 18(5.5 \%)$ \\
\hline & SII & $10 / 32(31.2 \%)$ \\
\hline & SIII & $20 / 50(40 \%)$ \\
\hline
\end{tabular}

CLND = complete lymph node dissection; NSLN = non-sentinel lymph nodes; $\mathrm{SLN}=$ sentinel lymph node. 


\section{Overall survival}

The median follow-up is 2.5 years (range: 6 months -9.6 years). Univariate analysis of OS was performed for all the parameters reported in Table 1.

The OS univariate analyses showed that the variables with a statistical prognostic significance were the same found to be associated with the higher percentage of NSLN involvement, in particular Breslow thickness $>2 \mathrm{~mm}$ (5-year rate: $87.4 \%$ vs $50.8 \% ; p=0.0069$ ), ulceration (5-year rate: $67.9 \%$ vs $41.3 \% ; p=$ $0.0495)$ and SLN micro-/macro-metastatic pattern (63.1\% vs 35\%; $p=0.0190)$ ( Fig. 1).

The OS was thereafter calculated on the basis of the presence of no adverse indicators, one, two or more. The 5 -year survival rate was $84.4 \%$ in patients without adverse parameters and $66.6 \%$ in patients with one adverse factor. A striking reduction in 5-year OS was found in patients with two or more adverse indicators $(38.3 \%)(p<0.001)$.

\section{Table 2}

Univariate and multivariate logistic regression.

\begin{tabular}{|c|c|c|c|}
\hline & $p$ & Odds ratio & $\begin{array}{l}95 \% \text { Confidence } \\
\text { interval }\end{array}$ \\
\hline \multicolumn{4}{|l|}{ Univariate logistic regression } \\
\hline Breslow & 0.0020 & 1.5211 & $1.1640-1.9877$ \\
\hline Ulceration & 0.0013 & 4.5948 & $1.8174-11.6168$ \\
\hline $\begin{array}{l}\text { Micro-/macro-metastatic } \\
\text { pattern of SLN involvement }\end{array}$ & 0.010 & 6.4167 & $1.5341-26.8379$ \\
\hline Starz classification & 0.013 & 2.3208 & $1.1977-4.4976$ \\
\hline \multicolumn{4}{|l|}{ Multivariate logistic regression } \\
\hline Breslow & 0.0498 & 1.3499 & $1.0002-1.8302$ \\
\hline Ulceration & 0.005 & 4.6686 & $1.6087-13.5487$ \\
\hline $\begin{array}{l}\text { Micro-/macro-metastatic } \\
\text { pattern of SLN involvement }\end{array}$ & 0.016 & 7.2665 & $1.4400-36.6676$ \\
\hline Starz classification & 0.1660 & 1.7449 & $0.7930-3.8390$ \\
\hline
\end{tabular}

\section{Discussion}

Yet considerable effort has been spent in trying to identify which positive SLN patients are likely to harbour NSLN metastases. Waiting for the final results of the Multicenter Selective Lymphadenectomy Trial (MSLT-II) that will aid to choose the necessary treatment based on different analysed factors, at the moment literature evidences are conflicting. In fact, even if several clinico-pathologic characteristics related to both primary melanoma (tumour thickness, ulceration, site and histological subtype) and SLN (number of 
positive SLNs, SLN tumour size) have been associated to the NSLN status, the results of different studies were controversial and some of them definitely failed to identify any parameter able to predict NSLN involvement [8], [9] and [28].

These evidences prompted us to try to identify in our positive SLN patients the most relevant parameters for the prediction of NSLN metastatic involvement and to ascertain whether clinico-pathologic SLN features correlate to the clinical course in terms of OS. Our aim was to identify variables easy to measure and reproducible to combine at the hope to identify clinically useful predictors of NSLN involvement and significant on OS. For that reason, we did not include in our analysis the SLN tumour burden, even if many studies have found the size of the metastatic deposits in the SLN to be predictive of NSLN involvement [7], [9], [10] and [11]. Also recently, Cadili et al. [21] confirmed the prognostic relevance of SLN total tumour size on both NSLN involvement and disease course in a large melanoma patient cohort. However, there is not agreement on the different features to be considered as predictive for NSLN involvement; moreover, the differences of methods applied to measure tumour size in SLN represent a major impediment to the comparison between the different studies [12], [13], [14], [15], [16], [17], [18], [19], [20] and [21]. The EORTC Melanoma Group suggested to stratify tumour burden into three categories namely $<0.1 \mathrm{~mm}, 0.1-1.0 \mathrm{~mm}$ or $>1.0 \mathrm{~mm}$ [29]. Other authors suggested different cut-off point in terms of size measures: more or less than $2 \mathrm{~mm}$ according to Roka et al. [8] or more or less than $1 \mathrm{~mm}$ according to Dewar [30]. The latter author found that, a part from the tumour size, also the micro-anatomic location of SLN metastases was predictive for NSLN involvement suggesting that patients with only sub-capsular deposits could be spared from CLND.

The main result of our study is that we were able to identify three variables significantly associated with a higher risk of NSLN metastases (Breslow thickness, ulceration, SLN micro-/macro-metastatic pattern). The same variables were found to play an unfavourable prognostic role on OS. Several papers have already showed that the pattern of SLN involvement [7], [17], [18] and [19] as well as the number of positive SLNs [19] were predictive on the NSLN involvement, as the Starz classification that the same author utilized in the classification of 2001 [31] and 2004 [17]. That revision is relatively simple to measure because needs only of a micrometer ocular and its usefulness have also been confirmed by recent works [32]. In our experience, the number of positive SLNs was not associated to an increasing NSLN involvement, whilst the prognostic relevance of Starz classification was ascertained in univariate but not confirmed in multivariate logistic regression analysis. The predictive value of Breslow thickness on NSLN involvement has been found in some previous papers, but not confirmed by others [10], [13], [14], [15], [20], [31] and [33]; the same happens for ulceration, thus confirming a great deal of variability which limits the drawing of definite conclusions. Some studies suggested also to consider the association of two or more variables. In fact Frankel et al. [19] utilized the relation between percentage of the surface area of the metastases on SLN and Breslow thickness while Reeves et al. [20] utilized S/U score (size of metastases on SLN/ulceration).

As a second step in our study, we showed that the likelihood of NSLN involvement increased in our patients along with the number of adverse indicators (Breslow thickness $>2 \mathrm{~mm}$; ulceration; macrometastatic pattern of SLN invasion) from $4.3 \%$ in patients without adverse features up to $55.9 \%$ when two or three adverse factors were present. Therefore, our results do suggest that in selected cases with significant co-morbidities and/or elderly age, the finding of no adverse prognostic indicators could be useful in identifying patients not to treat by regional node dissection. In these patients, a strict follow-up program with radiological work-ups such as nodal ultrasound and/or positron emission tomography plus computed tomography (PET/CT) could be applied. Ultrasonography associated with Doppler evaluation is of choice in the monitoring of the regional basin, in as much as its sensibility in the detection of occult nodal metastases is approaching 90\%; ultrasound utility is now being evaluated by the MSLT-II trial. On the other hand, PET/TC has a diagnostic accuracy superior to that of TC alone in the early detection of visceral metastases 
whilst its sensitivity in the evaluation of node metastases appears to be lower due to the fact that tumour deposits can be far below its detection threshold [34], [35] and [36].
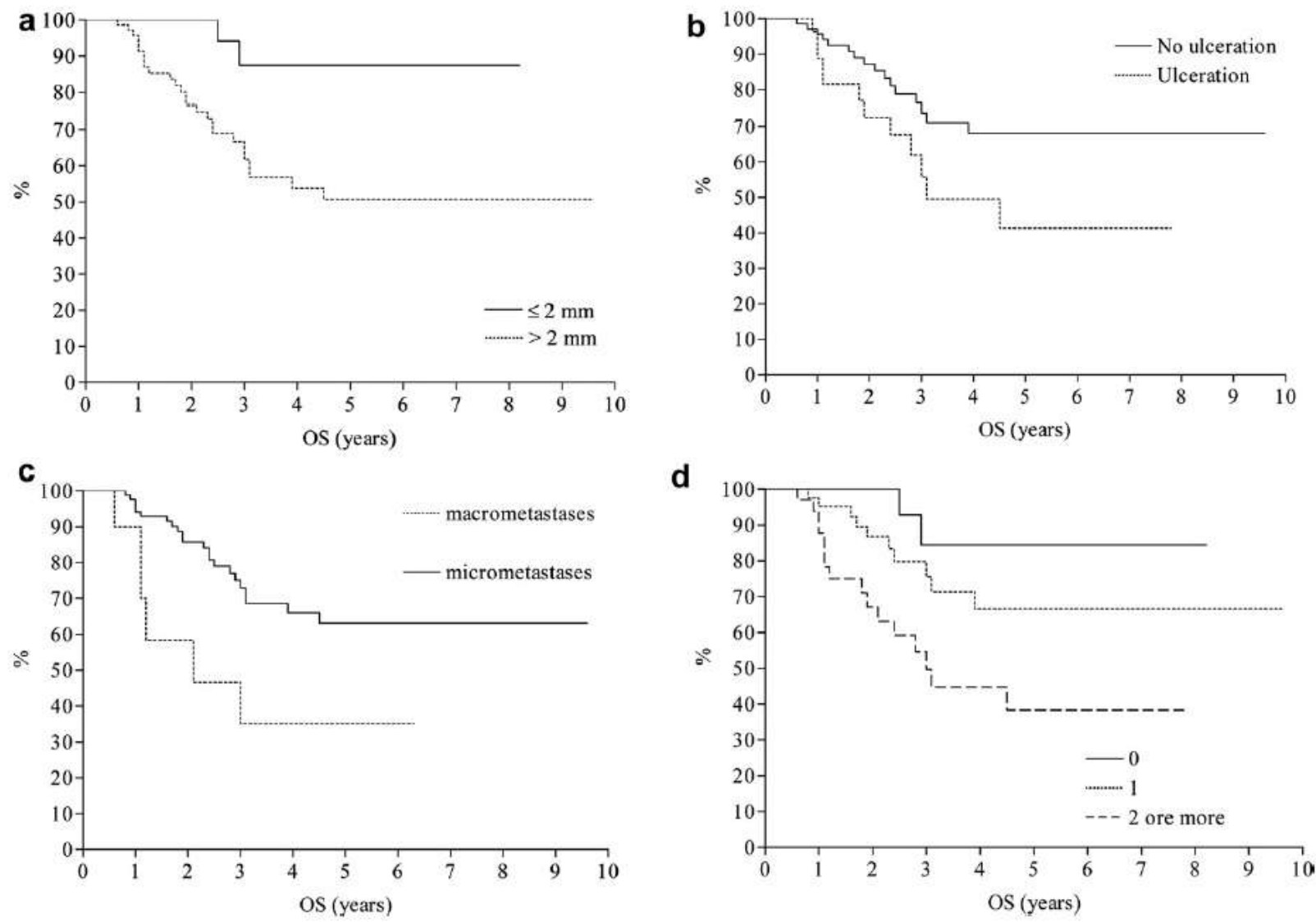

Figure 1. Overall Survival (OS) according to prognostic indicators: a) Breslow thickness $>2 \mathrm{~mm}(p=0.0069)$; b) ulceration ( $p=0.0495)$ c) SLN micro-/macro-metastatic pattern ( $p=0.0190)$; $d)$ number of adverse prognostic indicators $(0,1,2$ or more; $p<0.001)$.

Another controversial point is the impact of SLN features on OS. In comparison with the high literature coverage of NSLN involvement predictive factors, few data are reported on this latter topic. Previous studies indicated that the dimensions of nodal tumour deposits could be significant predictors [37] and [38]. Roka et al. [8] reported an SLN tumour size $>2 \mathrm{~mm}$, presence of NSLN involvement and Breslow thickness to be associated with different recurrence-free and disease-specific survival and confirmed the prognostic relevance of the S/U score proposed by Reeves et al. [20] In another paper, the presence of micro-metastatic tumour deposits in SLN was associated to a significantly better prognosis with respect to macrometastases [9]. A recent German study [39] found the greatest dimension of the largest tumour cell deposit, the tumour penetrative depth and capsular involvement as independent parameters for relapsefree and overall survival. The invasion depth (Starz classification) [17] was also found by previous studies to best predict overall survival [16], [18] and [40]. In our experience, however, Starz classification failed to 
disclose a significant association with a different clinical course, as well as the number of positive SLNs. It is interesting to note that our study found that the same variables associated with a higher likelihood of NSLN involvement carried also a prognostic impact on OS. However, it could be hypothesized that these variables may not have a prognostic impact on their own but only depending on their association with NSLN involvement. To this aim, we separated our patients according to NSLN involvement into two groups (presence or absence of melanoma cells) and we analysed in both groups the OS of patients according to the Breslow thickness, ulceration and micro-/macro-metastatic pattern (data not shown). The number of adverse prognostic indicators maintained a statistically significant association with the disease course not only in patients without NSLN involvement $(p=0.001)$ but also in patients harbouring NSLN metastases $(p=$ 0.05 ) even with a lesser degree of evidence. These results suggest therefore that the evaluation of the factors emerged from our study maintain a potential prognostic significance to be considered together with the well-known significance of NSLN score.

In conclusion, this study suggests a clinically useful and an easily applicable means of identifying melanoma patients with a potentially more unfavourable disease course on the basis of the concomitant evaluation of Breslow thickness, ulceration and SLN micro/macro-metastatic pattern. The presence of at least one of these adverse factors identify patients in whom CLND is mandatory; these patients should be included thereafter in a more strict follow-up program with more frequent clinical visits and radiological procedures given the unfavourable prognosis. On the other hand, the finding of no adverse indicators identify patients who could be spared from CLND in the presence of significant co-morbidities or elderly age. The relatively low number of patients included in this single centre study and the absence of a control group for validation, limit the achievement of more insights into this controversial topic for which the conclusions of the MSLT-II trial are awaited.

\section{Conflict of interest statement}

None declared.

\section{Authorship statement}

Guarantor of the integrity of the study: MG Bernengo, P Savoia, P Quaglino

Study concepts: S Ribero, S Osella-Abate

Study design: S Ribero, P Quaglino

Definition of intellectual content: S Osella-Abate, P Quaglino, P Savoia

Literature research: $S$ Ribero

Clinical studies: G Macripò, M Grassi, V Caliendo, P Quaglino

Experimental studies: -

Data acquisition: S Ribero, L Macrì, S Asioli, A Sapino, G Macripò

Data analysis: S Ribero, P Quaglino, S Osella-Abate

Statistical analysis: S Ribero, S Osella-Abate, P Quaglino

Manuscript preparation: $P$ Quaglino, S Osella-Abate, S Ribero

Manuscript editing: S Osella-Abate, S Ribero

Manuscript review: P Quaglino, P Savoia, G Macripò, MG Bernengo 


\section{References}

[1] D.L. Morton, D.R. Wen, J.H. Wong, J.S. Economous, L.A. Cagle, F.K. Storm et al. Technical details of intraoperative lymphatic mapping for early stage melanoma. Arch Surg, 127 (4) (1992), pp. 392-399

[2] J.E. Gershenwald, W. Thompson, P.F. Mansfield, J.E. Lee, M.I. Colome, C.H. Tseng et al. Multiinstitutional melanoma lymphatic mapping experience: the prognostic value of sentinel lymph node status in 612 stage I or II melanoma patients. J Clin Oncol, 17 (3) (1999), pp. 976-983

[3] C.M. Balch, J.E. Gershenwald, S.J. Soong, J.F. Thompson, M.B. Atkins, D.R. Byrd et al. Final version of 2009 AJCC melanoma staging and classification. J Clin Oncol, 27 (36) (2009), pp. 6199-6206

[4] D.L. Morton, J.F. Thompson, A.J. Cochran, N. Mozzillo, R. Elashoff, R. Essner et al. Sentinel-node biopsy or nodal observation in melanoma. N Engl J Med, 355 (13) (2006), pp. 1307-1317

[5] A.C. Van Akkooi, M.G. Bouwhuis, A.N. Van Geel, R. Hoedemaker, C. Verhoef, D.J. Grunhagen et al. Morbidity and prognosis after therapeutic lymph node dissections for malignant melanoma. Eur J Surg Oncol, 33 (2007), pp. 102-108

[6] P.C. Baas, H. Schraffordt Koops, H.J. Hoekstra, J.J. van Bruggen, L.T. van der Weele, J. Oldhoff. Groin dissection in the treatment of lowe- extremity melanoma. Short-term and long-term morbidity. Arch Surg, 127 (1992), pp. 281-286

[7] I. Satzger, B. Volker, A. Meier, A. Kapp, R. Gutzmer. Criteria in sentinel lymph nodes of melanoma patients that predict involvement of nonsentinel lymph nodes. Ann Surg Oncol, 15 (6) (2008), pp. 17231732

[8] F. Roka, P. Mastan, M. Binder, I. Okamoto, M. Mittlboeck, R. Horvat et al. Prediction of non-sentinel node status and outcome in sentinel node-positive melanoma patients. Eur J Surg Oncol, 34 (2008), pp. $82-88$

[9] M. Guggenheim, R. Dummer, F.J. Jung, D. Mihic-Probst, H. Steinert, V. Rousson et al. The influence of sentinel lymph node tumour burden on additional lymph node involvement and disease-free survival in cutaneous melanoma-a retrospective analysis of 392 cases. Br J Cancer, 98 (12) (2008), pp. 1922-1928

[10] A.J. Cochran, D.R. Wen, R.R. Huang, H.J. Wang, R. Elashoff, D.L. Morton. Prediction of metastatic melanoma in nonsentinel nodes and clinical outcome based on the primary melanoma and the sentinel node. Mod Pathol, 17 (7) (2004), pp. 747-755

[11] J.E. Gershenwald, R.H. Andtbacka, V.G. Prieto, M.M. Johnson, A.H. Diwan, J.E. Lee et al. Microscopic tumour burden in sentinel lymph nodes predicts synchronous nonsentinel lymph node involvement in patients with melanoma. J Clin Oncol, 26 (26) (2008), pp. 4296-4303

[12] R.A. Scolyer, L.X. Li, S.W. McCarthy, H.M. Shaw, J.R. Stretch, R. Sharma et al. Immunohistochemical stains fail to increase the detection rate of micrometastatic melanoma in completion regional lymph node dissection specimens. Melanoma Res, 14 (2004), pp. 263-268

[13] J.D. Wagner, M.S. Gordon, T.Y. Chuang, J.J. Coleman 3rd, J.T. Hayes, S.H. Jung et al. Predicting sentinel and residual lymph node basin disease after sentinel lymph node biopsy for melanoma. Cancer, 89 (2000), pp. 453-462 
[14] G.I. Salti, T.K. Das Gupta. Predicting residual lymph node basin disease in melanoma patients with sentinel lymph node metastases. Am J Surg, 186 (2003), pp. 98-101

[15] M.S. Sabel, K. Griffith, V.K. Sondak, L. Lowe, J.L. Schwartz, V.M. Cimmino et al. Predictors of nonsentinel lymph node positivity in patients with a positive sentinel node for melanoma. J Am Coll Surg, 201 (2005), pp. $37-47$

[16] I.M. Van der Ploeg, B.B. Kroon, N. Antonini, R.A. Valdés Olmos, O.E. Nieweg. Is completion lymph node dissection needed in case of minimal melanoma metastasis in the sentinel node? Ann Surg, 249 (2009), pp. 1003-1007

[17] H. Starz, K. Siedlecki, B.R. Balda. Sentinel lymphonodectomy and s-classification: a successful strategy for better prediction and improvement of outcome of melanoma. Ann Surg Oncol, 11 (3 Suppl) (2004), pp. 162S-168S

[18] I.M. Van der Ploeg, B.B. Kroon, N. Antonini, R.A. Valdés Olmos, O.E. Nieweg. Comparison of three micromorphometric pathology classifications of melanoma metastasis in the sentinel node. Ann Surg, 250 (2009), pp. 301-304

[19] T.L. Frankel, K.A. Griffith, L. Lowe, S.L. Wong, C.K. Bichakjian, A.E. Chang et al. Do micromorphometric features of metastatic deposits within sentinel nodes predict nonsentinel lymph node involvement in melanoma? Ann Surg Oncol, 15 (9) (2008), pp. 2403-2411

[20] M.E. Reeves, R. Delgado, K.J. Busam, M.S. Brady, D.G. Coit. Prediction of nonsentinel lymph node status in melanoma. Ann Surg Oncol, 10 (2003), pp. 27-31

[21] A. Cadili, M. Smylie, J. Danyluk, K. Dabbs. Prediction of nonsentinel lymph node metastasis in malignant melanoma. J Surg Res, 154 (2009), pp. 324-329

[22] P. Quaglino, L. Borgognoni, U. Bottoni, S. Calvieri, P. Carli, C. Catricalà et al. Italian guidelines for staging and follow-up of stage I-II cutaneous melanoma patients. G Ital Dermatol Venereol, 142 (2007), pp. 4147

[23] A.J. Cochran, B.R. Balda, H. Starz, D. Bachter, D.N. Krag, C.W. Cruse et al. The Augsburg consensus. Techniques of lymphatic mapping, sentinel lymphadenectomy, and completion lymphadenectomy in cutaneous malignancies. Cancer, 89 (2000), pp. 236-241

[24] A.J. Sober, T.Y. Chuang, M. Duvic, E.R. Farmer, J.M. Grinchnik, A.C. Halpern et al. Guidelines of care for primary cutaneous melanoma. J Am Acad Dermatol, 45 (4) (2001), pp. 579-586

[25] M.G. Cook, S. Di Palma. Pathology of sentinel lymph nodes for melanoma. J Clin Pathol, 6 (2008), pp. 897-902

[26] E.L. Kaplan, P. Meier. Non-parametric estimation from incomplete observations. J Am Stat Assoc, 53 (1958), pp. 475-480

[27] N. Mantel. Evaluation of survival data and two new rank order statistics arising in its consideration. Cancer Chemother Rep, 50 (1966), pp. 163-170

[28] K.M. McMasters, S.L. Wong, M.J. Edwards, C. Chao, M.I. Ross, R.D. Noyes et al. Frequency of nonsentinel lymph node metastasis in melanoma. Ann Surg Oncol, 9 (2) (2002), pp. 137-141 
[29] A.C. van Akkooi, A. Spatz, A.M. Eggermont, M. Mihm, M.G. Cook. Expert opinion in melanoma: the sentinel node; EORTC melanoma group recommendations on practical methodology of the measurement of the microanatomic location of metastases and metastatic tumour burden. Eur J Cancer, 45 (16) (2009 Nov), pp. 2736-2742

[30] D.J. Dewar, B. Newell, M.A. Green, A.P. Topping, B.W. Powell, M.G. Cook. The microanatomic location of metastatic melanoma in sentinel lymph nodes predicts nonsentinel lymph node involvement. J Clin Oncol, 22 (16) (2004 Aug 15), pp. 3345-3349

[31] H. Starz, B.R. Balda, K.U. Krämer, H. Büchels, H. Wang. A micromorphometry-based concept for routine classification of sentinel lymph node metastases and its clinical relevance for patients with melanoma. Cancer, 91 (11) (2001), pp. 2110-2121

[32] R. Younan, A. Bougrine, K. Watters, A. Mahboubi, M. Bouchereau-Eyegue, A. Loufi et al. Validation study of the $S$ classification for melanoma patients with positive sentinel nodes: the Montreal experience. Ann Surg Oncol, 17 (5) (2010), pp. 1414-1421

[33] J.H. Lee, R. Essner, H. Torisu-Itakura, L. Wanek, H. Wang, D.L. Morton. Factors predictive of tumorpositive nonsentinel lymph nodes after tumor-positive sentinel lymph node dissection for melanoma. J Clin Oncol, 22 (18) (2004), pp. 3677-3684.

[34] F. Amersi, D.L. Morton. The role of sentinel lymph node biopsy in the management of melanoma. Adv Surg, 41 (2007), pp. 241-256

[35] A. Forschner, T.K. Eigentler, A. Pflugfelder, U. Leiter, B. Weide, L. Held et al. Melanoma staging: facts and controversies. Clin Dermatol, 28 (3) (2010 May-Jun), pp. 275-280

[36] F. Jiménez-Requena, R.C. Delgado-Bolton, C. Fernández-Pérez, S.S. Gambhir, J. Schwimmer, J.M. PérezVázquez et al. Meta-analysis of the performance of (18)F-FDG PET in cutaneous melanoma. Eur J Nucl Med Mol Imaging, 37 (2) (2010 Feb), pp. 284-300

[37] J.M. Ranieri, J.D. Wagner, R. Azuaje, D. Davidson, S. Wenck, J. Fyffe et al. Prognostic importance of lymph node tumor burden in melanoma patients staged by sentinel node biopsy. Ann Surg Oncol, 9 (10) (2002), pp. 975-981

[38] G.W. Carlson, D.R. Murray, R.H. Lyles, C.A. Staley, A. Hestley, C. Cohen. The amount of metastatic melanoma in a sentinel lymph node: does it have prognostic significance? Ann Surg Oncol, 10 (5) (2003), pp. $575-581$

[39] A. Meier, I. Satzger, B. Völker, A. Kapp, R. Gutzmer. Comparison of classification systems in melanoma sentinel lymph nodes-an analysis of 697 patients from a single center. Cancer, 116 (13) (2010), pp. 3178-3188

[40] C.R. Rossi, G.L. De Salvo, E. Bonandini, S. Mocellin, M. Foletto, S. Pasquali et al. Factors predictive of nonsentinel lymph node involvement and clinical outcome in melanoma patients with metastatic sentinel lymph node. Ann Surg Oncol, 15 (4) (2008 Apr), pp. 1202-1210 